\title{
POTENCIAL DE CRESCIMENTO DE Chlorella vulgaris EM EFLUENTES SUÍNOS PARA PRODUÇÃO DE BIODIESEL ${ }^{1}$
}

Sidney de Oliveira Novaes Junior ${ }^{2}$, Samuel Nelson Melegari Junior ${ }^{3}$, Nyamien Yahaut Sebastien ${ }^{4}$, Priscila Ferri Coldebella $^{5}$, Elias Trevisan ${ }^{6}$, Douglas Rafael Aguiar ${ }^{7}$

${ }^{1}$ Aceito para publicação, $1^{\circ}$ trimestre de 2013.

${ }^{2}$ Licenciado em Ciências Biológicas pela Faculdade União das Américas - UNIAMÉRICA, Graduado em Direito pelas Faculdades Unificadas de Foz do Iguaçu - UNIFOZ, Pós Graduado em Gestão Ambiental pela Faculdade Pe. João Bagozzi e Mestrando em Bioenergia pela UNIOESTE, campus de Cascavel.

${ }^{3}$ Doutor em Planejamento de Sistemas Energéticos pela UNICAMP-FEM, professor associado B da Universidade do Oeste do Paraná (UNIOESTE).

${ }^{4}$ Doutor em Engenharia Ambiental pela Escola de Engenharia de São Carlos/SP.

${ }^{5}$ Doutoranda em Engenharia Química pela Universidade Estadual de Maringá (UEM).

${ }^{6}$ Doutorando em Engenharia Química pela Universidade Estadual de Maringá (UEM).

${ }^{7}$ Mestre em Bioenergia pela Universidade Estadual de Maringá (UEM).

Palavras-chave: Biodiesel, microalgas, lipídios, efluentes, suínos.

\section{Resumo}

Estudos recentes apontam que as microalgas possuem grande potencial para produção de lipídios que possam se transformar em biodiesel. Este trabalho objetivou estudar a Chlorella vulgaris e verificar seu perfil de ácidos graxos, tendo os efluentes suínos como substrato. Foram feitos quatro ensaios para verificar os percentuais de gordura produzida. Os componentes nitrogenados e fosfatados que servem de fonte de nutrição para as microalgas foram analisados, constatando-se a presença desses componentes em concentrações satisfatórias. Após a extração dos lipídios, fez-se a caracterização dos ácidos graxos presentes através da cromatografia gasosa. Foram encontrados vários ésteres que formam a base do biodiesel, conforme especificações da ANP.

\section{Introdução}

Durante o século passado, os combustíveis fósseis estiveram em evidência no cenário energético mundial, respondendo, naquela época, por cerca de $60 \%$ do consumo de energia do 
planeta (NASCIMENTO, 2009), sendo os combustíveis fósseis os maiores responsáveis por emissões de gases de efeito estufa (GEE). Por conta disso, alternativas ditas ecológicas estão sendo estudadas e viabilizadas com vários intuitos, mas especificamente, o de mitigar os efeitos relacionados às emissões de GEE (ALEJANDRA et al, 2010; BORGES, 2005; DEDÊ, 2010).

Visando um alcance mais imediato, o governo federal brasileiro fomenta oficialmente a pesquisa de formas alternativas de obtenção de energia para substituir os combustíveis fósseis (NASCIMENTO et al, 2009 e PAULILLO, 2009) e uma delas é o estudo de biocombustíveis, tendo as microalgas como fonte para esse tipo de biocombustível, por apresentarem potencial adequado para tal, em razão de suas características: custos baixos para a colheita e transporte; menor gasto de água, se comparado ao cultivo de plantas; as condições para seu cultivo não precisam ser necessariamente iguais às de culturas convencionais; podem ser cultivadas em meio salino, doce ou salobro; são excelentes fixadores de CO2. Além disso, as terras utilizadas podem ser desérticas e com alto índice de irradiação solar, podendo ser utilizados resíduos de outras produções, como o $\mathrm{CO} 2$ de processos industriais e resíduos orgânicos (TEIXEIRA, 2006).

\section{COMPOSIÇÃO DO BIODIESEL}

De acordo com a Resolução ANP 14/2012, em seu art. 2º biodiesel é "combustível composto de alquil ésteres de ácidos carboxílicos de cadeia longa, produzido a partir da transesterificação e ou/esterificação de matérias graxas, de gorduras de origem vegetal ou animal, e que atenda a especificação contida no Regulamento Técnico $n^{\circ}$ 4/2012" (ANP, 2012).

Conforme ensinam LÔBO et al (2009), o biodiesel é resultado de uma mistura de alquil ésteres de cadeia linear, obtida através da transesterificação dos triglicerídeos de óleos e gorduras com alcoóis de cadeia curta, tendo como coproduto o glicerol. Para a transesterificação desses óleos os alcoóis mais utilizados são o etanol e o metanol.

O metanol é o mais utilizado por ser mais reativo, implicando em menor temperatura e tempo de reação. Já o etanol é menos tóxico, renovável e produz biodiesel com mais cetonas e lubricidade. Entretanto, promove maior dispersão da glicerina, tornando difícil sua separação (LÔBO et al, 2009).

Em se tratando de normas de padrão de qualidade para biodiesel, as aplicadas pela americana ASTM (American Society of Testing and Materials) de número D6751e pela 
europeia CEN (Comité Européen de Normalisation) a EN 14214, são as mais usadas como referências para outras padronizações, inclusive a brasileira (LÔBO et al, 2009).

No Brasil, para que o biodiesel seja aceito, a Resolução 14/2012 da ANP impõe as especificações para os padrões de qualidade do combustível, conforme Regulamento Técnico da ANP nº 4/2012, constante da mesma Resolução.

\section{MICROALGAS COMO MATÉRIA-PRIMA PARA BIOCOMBUSTÍVEIS}

O rendimento em óleo é cerca de quinze vezes maior que o de palma, que é a oleaginosa de maior produtividade. A extração é simples, podendo ser feita por esmagamento ou ultrassom (NASCIMENTO et al., 2009), usando solvente, de forma fluida supercrítica, enzimática, por choque osmótico e extração ultrassônica assistida (AFIFY, 2010 e NASCIMENTO et al., 2009). Sua ecocompatibilidade é altamente eficiente, pois atende ao interesse principal que é a substituição gradual do diesel usado na maioria dos transportes de carga.

Grande parte dos estudos com microalgas tem como objetivo o resgate do $\mathrm{CO} 2$ da atmosfera, objetivando a diminuição do efeito estufa como forma de amenizar o aquecimento global. Entretanto, outros elementos fazem parte da nutrição daqueles microrganismos, como nitrogênio e fósforo. As concentrações desses nutrientes alteram substancialmente o desenvolvimento das microalgas, interferindo na produção de lipídios. As microalgas podem ser utilizadas para remover Nitrogênio e Fósforo de efluentes (BERTOLIN et al, 2003).

\section{NUTRIÇÃO ALTERNATIVA PARA MICROALGAS}

A proposta deste trabalho é o tratamento de efluentes suínos. É sabido que a suinocultura causa impactos ambientais de grande magnitude, pois é adotado o sistema de forma intensiva, acarretando em poluição de solos e mananciais de água (SILVA et al, 2012). Conforme PERDOMO et al (2001), o volume de dejetos suínos na Região Sul do Brasil ultrapassava 37 milhões de $\mathrm{m} 3$, mas hoje responde por quase $70 \%$ da criação desses animais em nosso País conforme a CIAS (EMBRAPA, 2011), com expectativa de crescimento da ordem de $22 \%$ nos próximos dez anos (UOL, 2013). Trata-se, portanto, de um gigantesco campo para cultivo de microalgas e, consequentemente, a geração de biodiesel. Sendo assim, a utilização de algas torna-se uma alternativa economicamente viável, por se tratar de mecanismo biológico com resultados altamente positivos (ARAÚJO et al, 2005). 
BECKER (1994) recomenda que os meios de cultura para microalgas possam ser agrupados em três tipos, dependendo das matérias-primas utilizadas e o fim dado à biomassa das microalgas: a) meio sintético completo; b) aqueles que são baseados em água natural enriquecida com suplementação mineral; e c) águas residuais como efluentes de estações de tratamento, industriais, etc.

Nesse contexto, o nitrogênio e o fósforo desempenham papel importante na nutrição das algas. BECKER (1994) mostra que a forma como ambos são fornecidos interfere em seu crescimento. As algas utilizam nitrogênio na forma de nitrato, nitrito, amônia ou ureia. Já o fósforo pode ser limitante do crescimento, mas em condições normais é absorvido na forma de ortofosfato, com dependência de energia fornecida por fotossíntese ou respiração celular (BECKER, 1994).

\section{Material e Métodos}

As cepas das microalgas Chlorella vulgaris foram obtidas junto ao Centro de Pesquisas em Aquicultura Ambiental (CPAA) da Universidade Estadual do Oeste do Paraná UNIOESTE, campus de Toledo.

Os meios de cultura selecionados para este trabalho foram os efluentes de suínos coletados na Granja Colombari, situada na cidade de São Miguel do Iguaçu/PR, onde há a criação de cinco mil suínos. As avaliações feitas pelo Instituto Ambiental do Paraná (IAP) com amostras de efluentes de suínos demonstram que a quantidade de nitrogênio e fósforo em diversas formas - Fósforo Total, Ortofosfato Solúvel, Nitrogênio Amoniacal, Nitrogênio Kjedahl e Nitrogênio Orgânico - atingiram concentrações diferenciadas, mas que seriam suficientes para nutrir as microalgas dos experimentos. Analisou-se também, nos Laboratórios NUCLEOTEC, o percentual de gordura nas amostras coletadas. Em ambas as análises foram utilizadas a metodologia descrita no Standard Methods (APHA, 2005).

\section{ESTRUTURA DE LABORATÓRIO}

Foi montada uma estrutura nos Laboratórios de Ciências Biológicas (CCBS), de Integração do Meio Ambiente (LIMA) e de Ciências Farmacêuticas (CCF) da Faculdade Anglo-Americano de Foz do Iguaçu, com duas estantes com fotoperíodo de 24 horas consecutivas e temperatura entre $25^{\circ} \mathrm{C}$ e $31^{\circ} \mathrm{C}$, com média de $28^{\circ} \mathrm{C}$. No LIMA, estão

localizados alguns equipamentos e materiais utilizados, que precederam e finalizaram o cultivo - microscópios, autoclave, capela, dessecadores, câmara de Neubauer, banho-maria e 
estufa. No CCF, está localizado o ultrassom, utilizado para o rompimento da parede celulósica e extração de lipídios das microalgas.

\section{CULTIVO DAS MICROALGAS}

Inicialmente, os efluentes foram autoclavados a $120^{\circ} \mathrm{C}$ por 30 minutos, a fim de eliminar os microrganismos existentes em cada efluente. Após a autoclavagem, tais culturas foram diluídas nas seguintes proporções:

- $\quad 10 \%, 1 \%, 0,5 \%$ e $0,3 \%$.

Foram inoculados $5 \mu \mathrm{L}$ de cultura de C. vulgaris a fim de se obter uma curva de crescimento para avaliar o potencial de crescimento das algas naqueles meios de cultura.

$\mathrm{Na}$ etapa seguinte, alterou-se a concentração dos efluentes para $20 \%$, sendo inoculados $10 \mu \mathrm{L}$ de culturas de C. vulgaris e deixadas por um período de 60 (sessenta) dias. Os cultivos foram feitos em quatro repetições. Após esse período, iniciou-se a etapa seguinte. Esta consistiu na filtração a vácuo, em filtrador da marca Quimis, modelo Q 355B, com filtros de $14 \mu \mathrm{m}$. Todos os filtros foram colocados em placas de Petri e depois em estufa a $40^{\circ} \mathrm{C}$ por 2 horas. Posteriormente, foram acondicionados em dessecadores para eliminar qualquer resquício de umidade.

\section{EXTRAÇÃO DE ÓLEOS}

A extração do óleo das microalgas foi feita usando a metodologia aplicada por DANTAS et al (2010). Após a dessecação, foram retiradas duas amostras de cada filtro e pesadas separadamente. Cada amostra foi introduzida em um tubo de ensaio previamente pesado e feita uma nova pesagem, agora com as amostras. Foram embalados em papel alumínio para evitar a ação da luz. Posteriormente, foram adicionados $5 \mathrm{~mL}$ de metanol como solvente. Os tubos contendo as amostras foram colocados em ultrassom a $40 \mathrm{kHz}$ durante 60 minutos, para efetuar a extração do óleo das microalgas. Após esse procedimento, as amostras foram retiradas e os tubos pesados somente com o óleo extraído.

\section{CROMATOGRAFIA GASOSA}

Para a determinação do perfil de ácidos graxos do óleo extraído foi utilizada cromatografia gasosa (VISENTAINER et al, 2006). A metodologia de transesterificação de lipídios com baixo teor de acidez que utilizada consiste em pesar $100 \mathrm{mg}$ do óleo em um tubo de ensaio, adicionar 2,0 mL de n-heptano e agitar até a solubilização total da matéria graxa. 
Em seguida adicionou-se 2,0 mL de solução 2 mol.L-1 de $\mathrm{KOH}$ em metanol e agitou-se novamente por cerca de cinco minutos. Após a completa separação das fases, o sobrenadante foi utilizado para injeção no cromatógrafo.

A análise cromatográfica das amostras seguiu os parâmetros adotados por METCALFE et al (1966). Foi utilizado um cromatógrafo da marca Varian, modelo CP 3800, com detector de ionização de chama (DIC), contendo uma coluna capilar específica para separação de ácidos graxos BP - X70 - SGE de 30m x 0,25mm. O gás utilizado para arraste foi o hélio, em razão split de 1:10. A análise foi realizada com programação de temperatura da coluna, iniciada a $140^{\circ} \mathrm{C}$, sendo aquecida até $250^{\circ} \mathrm{C}$ a $5^{\circ} \mathrm{C}$ min-1. A temperatura do detector foi mantida em $220^{\circ} \mathrm{C}$ e a do injetor em $260^{\circ} \mathrm{C}$.

A cromatografia gasosa utilizou os seguintes padrões de ácidos graxos: ácido caprílico (C8:0); ácido cáprico (C10:0); ácido láurico (C12:0) ácido mirístico (C14:0); ácido pentadecanoico (C15); ácido palmítico (C16:0); ácido palmitoleico (C16:1); ácido esteárico (C18:0); ácido oleico (C18:1); ácido linoleico (C18:2); ácido linolênico (C18:3); ácido ácido behênico (C22) e ácido lignocérico (C24). Tais ésteres foram metílicos foram identificados por comparação com os padrões cromatográficos através do tempo de retenção.

\section{Resultados e Discussões}

Os cultivos foram realizados com duração necessária para que houvesse uma curva de crescimento das espécies testadas, com as fases LAG, fase LOG ou exponencial, fase de estabilização e fase de declínio ou senescência. Tais cultivos apresentaram os seguintes resultados:

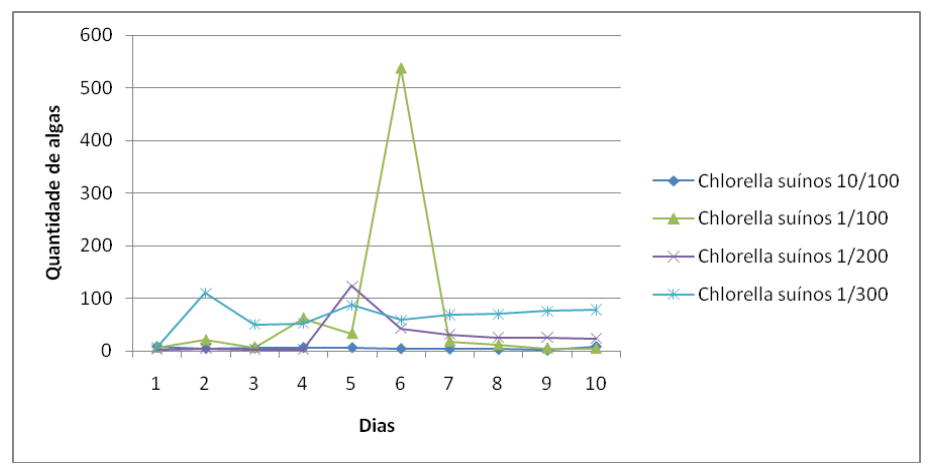

Figura 1: Curva de crescimento de Chlorella vulgaris em efluentes suínos

Verificou-se que não houve especificamente o desenvolvimento de todas as fases, mas sim um crescimento exponencial em determinadas situações. A concentração em $1 \%$ 
(1/100) de efluentes suínos permitiu que o cultivo de Chlorella chegasse a $537.10^{-4}$ cél. $\mathrm{mL}^{-1}$, no sexto dia. Dessa forma, vê-se que não houve um crescimento ideal, somente o crescimento exponencial.

Fez-se também um cultivo em concentração distinta, a fim de se estabelecer o potencial de produção de lipídios por parte das microalgas escolhidas. Tal cultivo apresentou o resultado demonstrado na Figura 2:

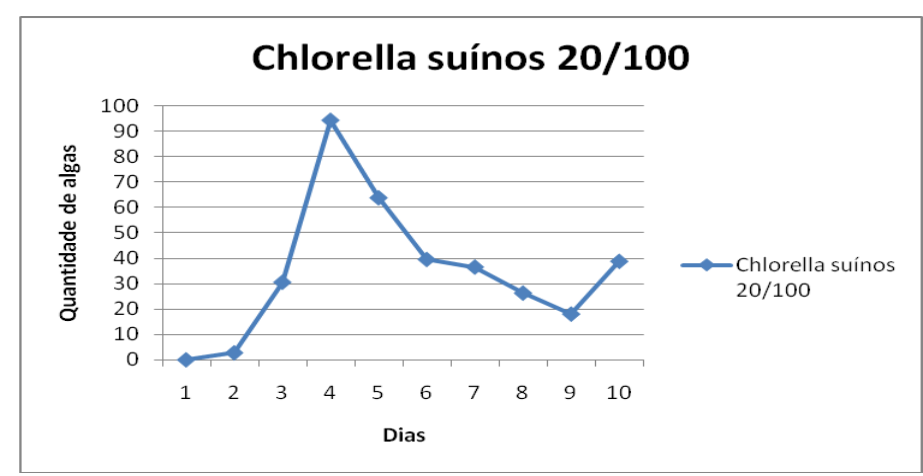

Figura 2: Cultivo de Chlorella vulgaris em efluentes suínos - concentração a $20 \%$

Tem-se aqui, a obtenção do melhor resultado no quarto dia, com 94,25.10-4 cél.mL ${ }^{-1}$ de $C$. vulgaris. O padrão cromatográfico está estabelecido na Figura 3.

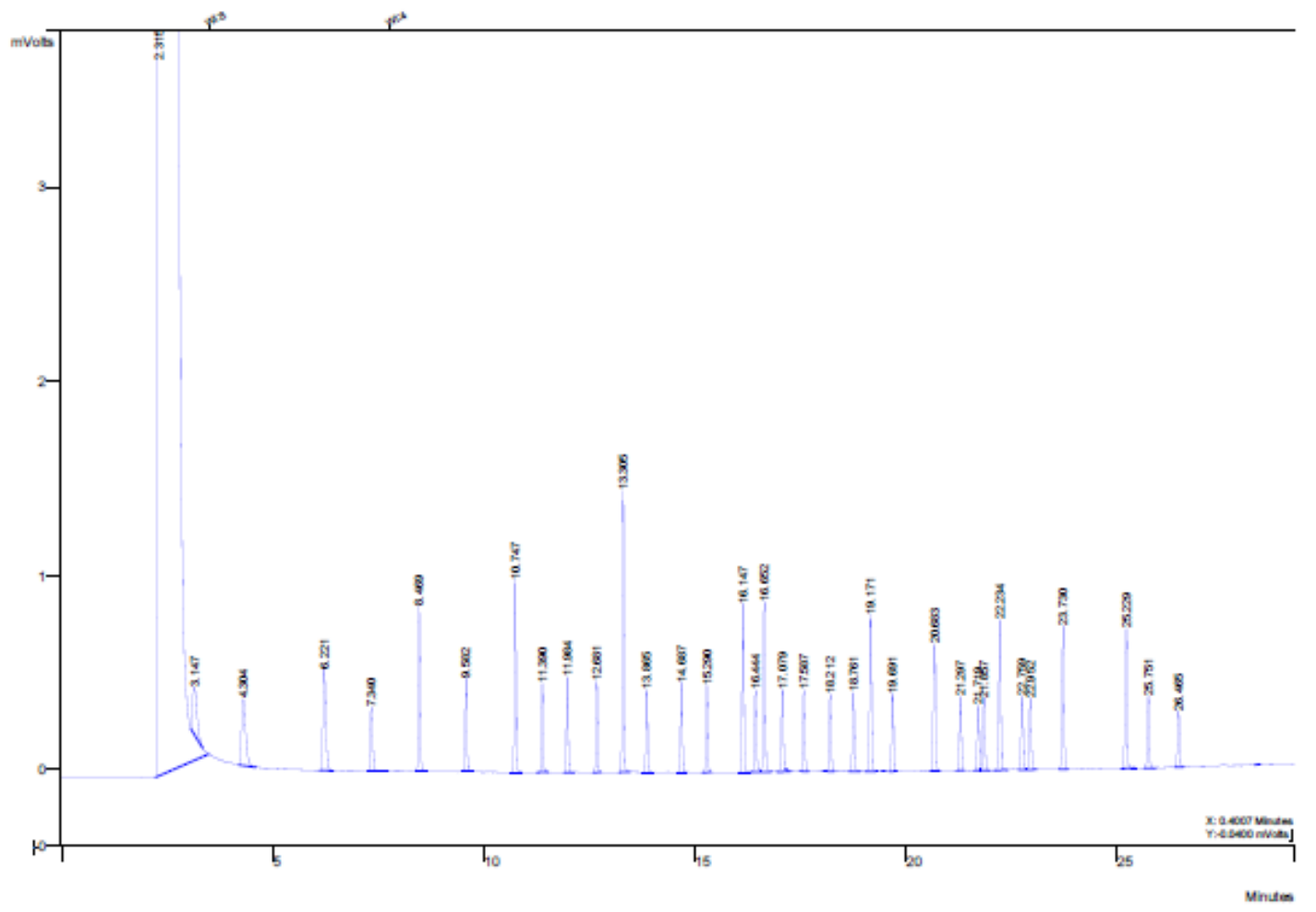

Figura 3: Padrão cromatográfico para análise de ésteres extraídos de Chlorella vulgaris Após análise cromatográfica, os resultados estão demonstrados na Figura 4: 


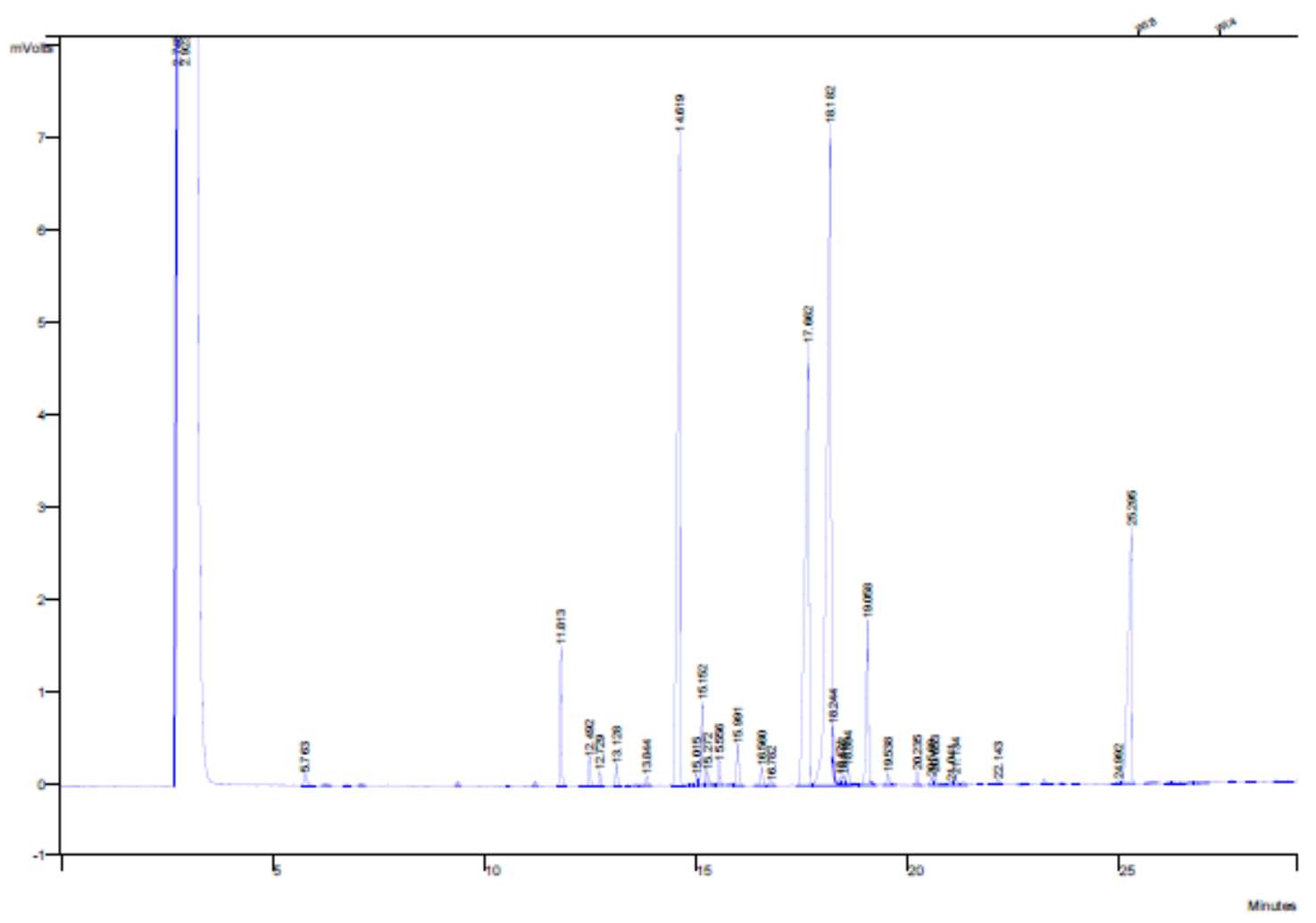

Figura 4: Análise cromatográfica dos ácidos graxos contidos nas amostras

Constatou-se a presença dos seguintes ácidos graxos: C13:0 = Tridecanoico $(5,763)$; C17:0 - Heptadecanoico (11,813); C17:1 - Heptadecanoico (12,492); C18:0 - Esteárico (13,874); C18:1 - Oleico (14,619); C18:2 - Linoleico (15,152); C18:3 - Linolênico (17,662); C20:0 - Araquídico (18,182); C21:0 - Heneicosanoico (19,058); e C20:3 - Eicosanotrienoico $(21,041)$.

\section{Conclusão}

Verificou-se que o cultivo de microalgas em efluentes suínos apresentou crescimento satisfatório e foi capaz de sintetizar os ésteres necessários à obtenção de biodiesel. Estudos posteriores poderão quantificar o percentual que foi utilizado da massa obtida. 


\section{Referências Bibliográficas}

1. AFIFY, A. E. M. R.; SHALABY, E. A.; SHANAB, S. M. M. Enhancement, of biodiesel production from different species of algae. Gizá, Egito. Out/dez 2010. Disponível em <http://grasasyaceites.revistas.csic.es/index.php > acesso em 18.out 2010.

2. ALEJANDRA, P. M.; CESAR, E. F.; JORGE, L. G. Microalgas: Potencial para la produccion de biodiesel. João Pessoa, PB. 2010. Disponível em <http://www.infoteca.cnptia.embrapa.br/bitstream/item/18289/1/BID-07.pdf> acesso em 01.out 2010.

3. AMERICAN PUBLIC HEALTH ASSOCIATION (APHA) 2005. Standard Methods for the Examination of Water and Wastewater. Standard Methods on line. 2005. Section 9060. Samples. Disponível em <http:www.standardmethods.org> acesso em 30 de maio de 2013.

4. AGÊNCIA NACIONAL DE PETRÓleO, GÁS NATURAL E BIOCOMBUSTÍVEIS (ANP), Estudo sobre as especificações internacionais para os biocombustíveis. Disponível em < http://www.anp.gov.br> acesso em 14.mai 2013.

5. ARAÚJO, W. E. L.; PASQUALETTO, A. Utilização de Algas no Tratamento de Efluente Doméstico. Goiânia, GO. 2005. Disponível em <,http://www.pucgoias.edu.br/ucg/prope/cpgss/ArquivosUpload/36/file/UTILIZA\%C3\%87 $\% \mathrm{C} 3 \% 830 \% 20 \mathrm{DE} \% 20 \mathrm{ALGAS} \% 20 \mathrm{NO} \% 20 \mathrm{TRATAMENTO} \% 20 \mathrm{DE} \% 20 \mathrm{EFLUENTE} \% 2$ 0DOM\%C3\%89STICO.pdf> acesso em 24.mar 2011.

6. BECKER, E. W. Microalgae - Biotechnology and Microbiology. Cambridge, UK. 1994. p. 11, 18-25.

7. Bertolin, T. B. P., COSTA. J. A. V., COllA, L. M., BERTOLIN, T. E., HEMKEMEIER, M.. Produção de Microalga Spirulina platensis a Partir de Efluente Suíno Sintético. Rio $\quad$ Grande/RS. $2003 . \quad$ Disponível em <http://www.enq.ufsc.br/eventos/sinaferm/trabalhos_completos/t269.doc> acesso em 27.abr 2013.

8. BORGES, L. V. Absorção do dióxido de carbono atmosférico por microalgas utilizadas na aquicultura para a geração de um mecanismo de desenvolvimento limpo (MDL). Rio Grande, RS. Mar 2005. Disponível em < http://bdtd.furg.br/tde_busca/arquivo.php?codArquivo=88> acesso em 21.nov.2010.

9. DEDÊ, M. A. B. Mecanismo de desenvolvimento limpo de etanol e biodiesel utilizando algas verdes a partir de uma metodologia para macrorredução, educação ambiental e o desenvolvimento sustentável. ENCICLOPÉDIA BIOSFERA, Centro Científico Conhecer, vol. 6, n. 9, pág. 9. Goiânia, GO. Disponível em <http://www.conhecer.org.br/enciclop/2010/mecanismo.pdf> acesso em 05.nov 2010.

10. DANTAS, D. M. M.; DRUMMOND, A. R. F.; SANTOS, L. B. G.; SANTOS, F. K.; BEZERRA, R. S.; GÁLVEZ, A. O. Extração de óleo de microalga utilizando ultrassom com diferentes solventes visando a produção de biodiesel. João Pessoa, PB. Disponível em <http://www.cbmamona.com.br > acesso em 07.ago 2012.

11. DATAR, M.T., BHARGAVA, D.S. Effects of environmental factors on nitrification during aerobic digestion of activated sludge. Journal of the Institution of Engineering (India), Part EN: Environmental Engineering Division, v.68, n.2, p.29-35, Feb. 1988. 
12. EMBRAPA Suínos e Aves. 2001. Disponível em $<$ http://www.cnpsa.embrapa.br/cias/index.php?option=com_content\&view=article\&id=59 $>$ acesso em 28.abr 2013.

13. FADINI, P.S. Quantificação de carbono dissolvido em sistemas aquáticos, através da análise por injeção em fluxo. Campinas, 1995. Dissertação de mestrado-Faculdade de Engenharia Civil-Universidade Estadual de Campinas, 1995.

14. LÔBO, I. P.; FERREIRA, S. L. C. Biodiesel: parâmetros de qualidade e métodos analíticos. Quim. Nova, vol. 32, $\mathrm{n}^{\circ}$ 6, Jul.2009. Disponível em < http://www.scielo.br/pdf/qn/v32n6/44.pdf> acesso em 19.mai 2013.

15. METCALFE, L. D., SCHMITZ, A. A., PELKA, J. R. Rapid Preparation of Fatty Acid Esters from Lipids for Gas Chromatographic Analysis. Washington, DC, EUA. Disponível em <http://pubs.acs.org/doi/abs/10.1021/ac60235a044> acesso em 29.abr 2013.

16. NASCIMENTO, I. A.; PEREIRA, S. A.; LEITE, M. B. N. L.; SANTOS, J. N.; NASCIMENTO, T. P.; NASCIMENTO, M. A.; NETO, J. B. C.; SOUSA, C. S. Microalgas como matéria-prima para biocombustíveis: importância no cenário atual, principais entraves e resultados promissores na Bahia. Dez 2009. DIÁLOGOS \& CIÊNCIA - Revista da Rede de Ensino FTC. Disponível em <http://dialogos.ftc.br> acesso em 01.out 2010.

17. PAUlillo, L. C. M. S.; JATOBÁ, F. H. P.; CECHINEL, C. A. Biodiesel: Eficiência energética e impacto ambiental. 23.jun 2010. Disponível em < http://www.gestaouniversitaria.com.br/edicoes/217-229/23052-biodiesel-eficienciaenergetica-e-impacto-ambiental.html>, acesso em 10.out 2010.

18. PERDOMO, C. C.; LIMA, G. J. M. M.; NONES, K. Produção de suínos e meio ambiente, Abr.2001. Gramado, RS. Disponível em <http://www.cnpsa.embrapa.br/sgc/sgc_publicacoes/anais0104_perdomo.pdf>, acesso em 27.abr 2013.

19. SILVA, C. L. S.; BASSI, N. S. S. Análise dos impactos ambientais no Oeste Catarinense e das tecnologias desenvolvidas pela Embrapa Suínos e Aves. Set.2012. Belém, PA. Disponível em <http://www.anppas.org.br/encontro6/anais/ARQUIVOS/GT7946-803-20120621110037.pdf> acesso em 27.abr 2013.

20. TEIXEIRA, C. M.; MORALES, M. E. Microalga como matéria-prima para a produção de biodiesel. 2006. Disponível em < www.biodiesel.gov.br/docs/congressso2006/agricultura/MicroalgaComo.pdf> acesso em 01.out 2010.

21. UOL - Seção Rural Centro. Ed. de 27/04/2013. Disponível em $<$ http://ruralcentro.uol.com.br/noticias/producao-de-suinos-no-brasil-vai-crescer-2256426> acesso em 28. abr 2013.

22. VISENTAINER, J. V.; FRANCO, M. R. B. Ácidos Graxos em óleos e gorduras: Identificação e quantificação, Ed. Varela, São Paulo, 2006. 